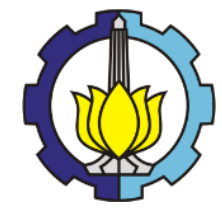

$8^{\text {th }}$ International Conference on

Architecture Research and Design (AR+DC)

November 1-2, 2016

ARHDC

\title{
Patterns and uses of mezzanine of low cost apartments in Surabaya
}

\author{
Rika Kisnarini ${ }^{\mathrm{a}^{*}}$ \\ ${ }^{a}$ Department of Architecture of ITS, Kampus ITS Keputih Sukolilo, Surabaya 60111, Indonesia \\ *Corresponding author. Tel.: +62 811310424; fax: +62 -31 8481827. \\ E-mail address: rika@arch.its.ac.id
}

\begin{abstract}
Dwelling today should provide an opportunity for residents to develop. The design of storey residential buildings including apartments for low-income community should be thought about how these poor families are also developing therefore their space requirement is also growing. Rusunawa in Surabaya is a simple multi-storey dwelling which is built to accommodate disadvantaged households. Usually the available space comprising: a multi-functional space, a kitchen, a bathroom / WC, and sometimes completed with a balcony. The space that can be lived in here is only the multi-functional space. So, only in this space the family take care all their activities both the private activities such as sleeping and storing money, as well as public activities such as entertaining, watching TV etc. Addition space at least for separating between their private and public activities is exactly needed. In this case, beside by partitioning, separating the multi-functional space by constructing a mezzanine is the best and most legal way for creating additional (private) space. This study aims to investigate the patterns and whatever uses of space that can be made by household residents of low cost apartments in Surabaya for their mezzanine dealing with their adapting action in meeting their spatial demands. A hundred of users living in Rusunawa spreading out in 14 locations in Surabaya are taken as samples. The methods applied are questionnaires and checklist. Results of study expected are patterns and uses of mezzanine.
\end{abstract}

Keywords: patterns and uses; mezzanine; rusunawa Surabaya

\section{Introduction}

One family that begins with the newlyweds will always grow and develop because this couple of marriage is almost certainly wants to have children who are expected to be able to complete their happiness. Families as occupants of housing units, including residents of Rusunawa, certainly evolve over time. Therefore, for the sake of sustainability of low cost apartment buildings, the design for the unit also needs to anticipate this development.

The space area of Rusunawa units in Surabaya that were built by the government, has been evolving from the beginning of the project that only an area of $22.5 \mathrm{~m}^{2}$, became $32 \mathrm{~m}^{2}$ on the most recent construction. However, the recent unit space area, which has already increased a lot, is still less spacious when compared to the real spatial needs of the residents. The real space area requirements, which are much greater than the living space provided by the government, resulted in the increase of space by residents which is done in inappropriate ways. Occupants in this case need to do adaptation to meet their space demand while the building is not designed to be adaptable. 


\section{Theory and Methods}

Dividing the level of adaptation based on its sophistication into 6: Flexible, Active, Dynamic, Interactive, Intelligent, and Smart (Lelieveld, Voorbij, \& Poelman, 2007). Adaptation which is referred in this paper is not that sophisticated. Even for the first level it does not qualify, for flexible architecture here is meant as flexibility. With flexible architecture the possibility of adjustments on specific components of the building is aimed. This action is in direct control of the user, which means that the component doesn't have the ability to change itself. The components of the building are changeable, with an external force. In fact the components of rusunawa are not changeable at all.

Adaptability according to (Kielion, 2008) is design to adjust to different functions, users and climate change. While according to (Cowee \& Schwehr, 2012) adaptability is being able to add another storey at a later date as well as anticipating the design of the slab construction. Slabs can be designed to accommodate future space requirement (gridded layout). Adaptability according to this theory seems to be the concept of adaptability which is the most appropriate for this paper. It will be better when it is associated with the adaptability that can be offered by the installment of mezzanine. Mezzanine floors give room for space to grow. Staircases are designed to suit floor heights and required widths, while complying with regulations. While a mezzanine floor is manufactured and constructed to specific requirements, the structure is often of a bolted steel construction, enabling easy extension, reengineering or relocation with significant cost savings. Mezzanine can even double the storage space, whilst increasing the existing floor area.

In adapting to the real spatial need dwellers of rusunawa often use corridor space to do activities that cannot be accommodated to be done within the unit. Some of them also utilized the balcony to be converted into inner living space, or expand the balcony area to suffice the storing space. In fact these actions were not permitted and were not legal. The only legal action they can do to meet the shortage of space is to increase space vertically by installing a

mezzanine. Unfortunately, not all Rusunawa in Surabaya allow the installation of a mezzanine because of inadequate unit space dimension, especially their critical unit space height.

As (Geraedts, 2009) said, buildings and building components must be able to be changed according to the changing user' demands. There should be capacity of the buildings to accommodate substantial functional change (Moffatt \& Russell, 2001). Otherwise the family cannot live happily and prosperously. In fact, this is indeed the government's main goal in developing Rusunawa that designated to disadvantaged families.

Although somewhat forced because of the additional space requirements, installation of a mezzanine can still be made, but its use will be very limited. For residents of low cost apartments in Surabaya, the use of space with limitations is common, they are accustomed to receiving what is available there. However, this situation is a responsibility of either the designer or architect, and especially the provider of units that is the government. As (West \& Emmitt, 2004) described, dwelling space should afford to fit the changing requirements at different time and stages of the development of family.

\subsection{Characteristics of mezzanine}

Mezzanine is a small floor between two main levels of a building and it is usually in the form of a balcony (Merriam-Webster's Learner's Dictionary). In a more fully definition mezzanine is a low-ceilinged story between two main stories of a building. It is an intermediate story that projects in the form of a balcony. Mezzanine is characterized as: 1 . an intermediate floor, similar to a balcony, in a building whose center is open to the doubleheight ceilinged floor below; 2. It is placed halfway up the wall on a floor which has a ceiling at least twice as high as a normal floor; 3. It does not count as one of the floors in a building, generally it does not count in determining maximum floor-space; 4. It may have lower-than-normal ceilings; 5. It doesn't imply a function, as mezzanines can be used for a wide array of purposes (https://en.wikipedia.org/wiki/Mezzanine)

\subsection{Spatial Adaptability and Flexibility}

Adaptability often coincides with the concepts such as flexibility. However, it is noticed that the important determinants of adaptability are generally changes of functions without changing characteristics. When elasticity means increasing or changing function by possibilities to attach or detach parts from other building parts, flexibility 
means changing of function by changing the technical structure at minimal costs and abruptions in operation (Bullen, 2007; Douglas, 2006). The concept of adaptability according to (Moffatt \& Russell, 2001) can be broken down into a number of simple strategies that are familiar to most designers: 1 . Flexibility or enabling minor shifts in space planning; 2. Convertibility or allowing for changes in use within the building; 3 . Expandability, (alternatively shrink-ability) or facilitating additions to the quantity of space in a building.

\subsection{Methods applied}

Methods of questionnaires and checklist were applied in this research to collect data of whichever activities taken cared by households in their daily life, as well as whichever location in their unit were used to conduct each activity. All of these were done in order to find how much space is actually needed by families in performing their daily activities. In this case the checklist is very helpful especially in pointing out where the location of each activity performed and how much space is used to perform each of these activities. Every activity involves whatever furniture is needed including how the moving space of the actors.

By attaining the broad of the real space needs which is in fact much larger than the space provided, then it is discovered why many occupants of Rusunawa did adaptation on their dwelling unit. Of course the answer is to meet the broad of the real space needs, because the existing space is not sufficient and does not provide an opportunity for residents to develop the space according to their needs.

\section{Adaptation in Rusunawa}

The result in calculation shows that the broad of the real space needs is averagely $35.46 \mathrm{~m} 2$, while the living space which is provided by the government is only $23.14 \mathrm{~m} 2$ on average. So the space shortage averagely is $12.32 \mathrm{~m} 2$. To meet their spatial needs occupants did various adaptations.

From investigation on adaptation which has been made by residents of Rusunawa in Surabaya that are scattered in 14 locations throughout the city, it can be obtained the following results. Of all 100 samples in the data collection, it was found that the most widely adaptation performed by occupants in overcoming the shortage of space is by dividing the multi-functional space using partitions which reaches $72 \%$. The next highest is the use of corridor space. There were 29 families who used the corridor space to meet their space requirement. Occupants who installed mezzanine on their unit were 16 families. Families who changed the function of their balcony into living space were as much as $13 \%$, while families who expanded balcony were $12 \%$.

This study concentrates on the vertical adaptation. First it should be understood that the installation of a mezzanine is the most legal action in order to cover the shortage of space. However, to realize this action, it requires not a small cost, also energy and ability to design the construction. Secondly, more fundamentally, not all units have a space height that allows the installation of this mezzanine. Perhaps these are the causes that make not many occupants did vertical adaptation in meeting their spatial demand.

The height of units in Rusunawa Surabaya varies starting from $2.65 \mathrm{~m}$ for the lowest to $3.40 \mathrm{~m}$ for the highest. But, units with height of $3.40 \mathrm{~m}$ only belong to Randu and Gunungsari, while the rests are lower units. However, they need to do adaptation. Therefore, many of them did other than vertical adaptation, such as by space partitioning, corridor occupation or balcony extension.

\section{Patterns and uses of mezzanine}

In installing the mezzanine, residents have their own ways and patterns. The results of the survey on vertical adaptation at Rusunawa in Surabaya shows that the pattern of mezzanine installation can be categorized into three groups: The first group put their mezzanine just less than half the size of multi-functional space area, it can be either to the left or to the right side; The second group were those who put the mezzanine right half the area of multifunctional space which cover half the floor area of the rear part; and the third group installed the mezzanine by covering the entire space of multi-functional space fully. 
Besides having their own patterns, residents also have their own way in terms of the holing of space to get into the space on mezzanines. Not only that, the way they provide stairs or a ladder to climb into the upper mezzanine space is also unique. All of these happened because of the limitations. What certainly limited are the space area and the cost. This is evidenced from the materials applied which seen as used materials. Moreover, rarely they were finalized with finishing touch. In terms of knowledge and experience about the construction, even need thumbs up, because they were able to create a strong enough construction although only supported by improvised techniques. The table below is the result of survey regarding how the patterns of mezzanine installment and the way of space holing for entering the mezzanine space, as well as the place and the angle of staircases or ladder installment.

Table 1. Patterns of mezzanine installed by residents.

\begin{tabular}{|c|c|c|c|c|c|c|c|c|c|c|c|}
\hline & \multirow{2}{*}{ Address } & \multicolumn{3}{|c|}{ Space Patterns } & \multicolumn{3}{|c|}{ Mezzanine Space Height } & \multicolumn{2}{|c|}{ Entry Holing } & \multicolumn{2}{|c|}{ Stairs/Ladder } \\
\hline & & $<1 / 2$ & Half & Full & Low & Mid & High & Floor & Wall & Angle & Perpendicular \\
\hline 1 & I - 408 Sombo & & & 1 & & & 1 & 1 & & & 1 \\
\hline 2 & Sombo & 1 & & & & & 1 & & 1 & 1 & \\
\hline 3 & I - 103 Sombo & & 1 & & & 1 & & 1 & & & 1 \\
\hline 4 & I - 402 Sombo & & 1 & & & & 1 & & 1 & 1 & \\
\hline 5 & I - 414 Sombo & & & 1 & & & 1 & & 1 & 1 & \\
\hline 6 & A - 406 Simo & & & 1 & & & 1 & 1 & & & 1 \\
\hline 7 & A - 309 Simo & & 1 & & & 1 & & & 1 & & 1 \\
\hline 8 & A - 402B Simo & & 1 & & & & 1 & & 1 & 1 & \\
\hline 9 & A - 407 Simo & 1 & & & & 1 & & 1 & & & 1 \\
\hline 10 & A - 315 Simo & & 1 & & & 1 & & 1 & & & 1 \\
\hline 11 & A - 308 Simo & & 1 & & & 1 & & 1 & & & 1 \\
\hline 12 & A - 302B Simo & & 1 & & & 1 & & & 1 & 1 & \\
\hline 13 & A -314 Simo & & 1 & & & 1 & & & 1 & 1 & \\
\hline 14 & A - 410 Simo & & 1 & & & 1 & & 1 & & & 1 \\
\hline 15 & E - 336 Dupak & & 1 & & & 1 & & 1 & & 1 & \\
\hline \multirow[t]{2}{*}{16} & D - 133 Dupak & & 1 & & & 1 & & 1 & & & 1 \\
\hline & & 2 & 11 & 3 & $\mathbf{0}$ & 10 & 6 & 9 & 7 & 7 & 9 \\
\hline
\end{tabular}

From the table above, it is seen that the mezzanine installment pattern which is most often made by the occupants of Rusunawa in Surabaya is the pattern of half the floor area with holing for entrance on the floor. The height of mezzanine space which is most common found is the medium height, where people cannot stand up in it, so people can only do kind of activities which is done by sitting or sleeping. The type of stairs that is widely seen is the staircase which is made perpendicular or with a slight slope. This is natural because the staircase had to be made in a very limited space.

\subsection{Patterns of less half the area}

Pattern of mezzanine installation in less half area is the least pattern found in this study. This could be because the height of the space does not permit the installation of a mezzanine normally due to the lowness of unit space. Of the 16 sample families who installed mezzanine in this study, there were only two who applied this kind of pattern.
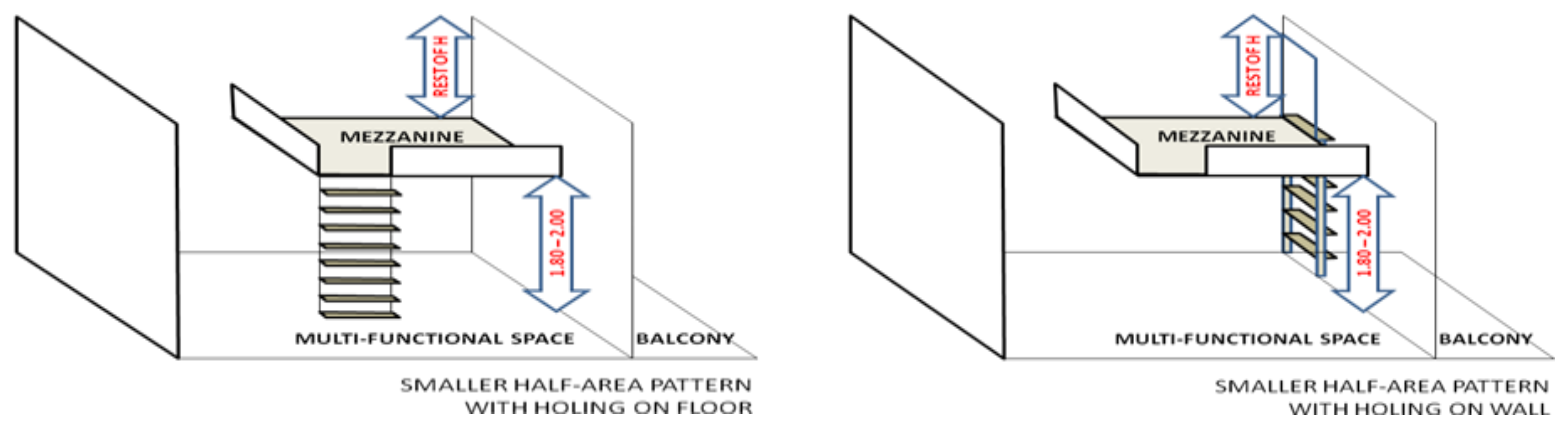

Fig. 1. Patterns of less half the area of mezzanine with holing on floor and wall. 
With the short height condition, the use of mezzanine space that can be expected is only as limited storing space. Therefore, the depth of space should also be just within the arm's reach. With a ladder that can be moved it will be able to facilitate the arrangement of the storage and the retrieval of goods which are stored here. Usually this type of mezzanine space is used for storing items that are considered good or valuable to the family, but rarely used. The storing items which is located above is considered more secure than simply placed on the floor or other place.
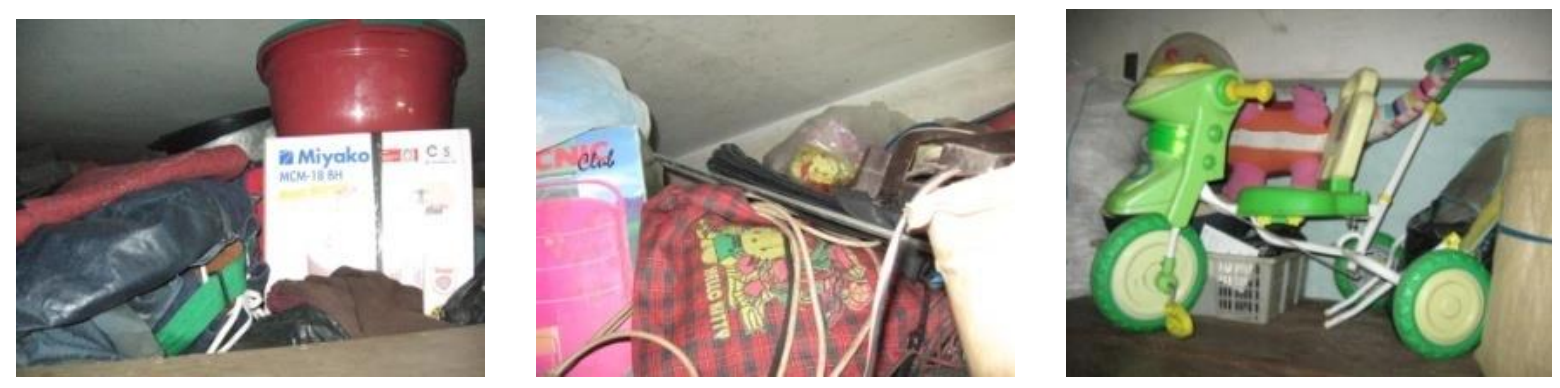

Fig. 2. Illustration of use of less half the area of mezzanine.

\subsection{Patterns of half the area}

Installation of mezzanine of half the space area with mediocre height is a pattern that is the most often made by the occupants of Rusunawa in Surabaya. The height of mezzanine space which is inadequate, makes the activities that can be done here is also limited. However, many household residents still did it.

This proves that the inhabitants of Rusunawa in Surabaya really need the extra space, while the existing of unit space condition does not provide opportunities for the vertical adaptation. Therefore, they keep doing the installation of a mezzanine, but the use of the resulting space is also very limited. In this case, the occupants had done the right thing. Pattern of half the space area deserved to be chosen, since with the height of existing unit space which is very low, installation of mezzanine that covers the entire floor of multi-functional space can lead to severely discomfort.
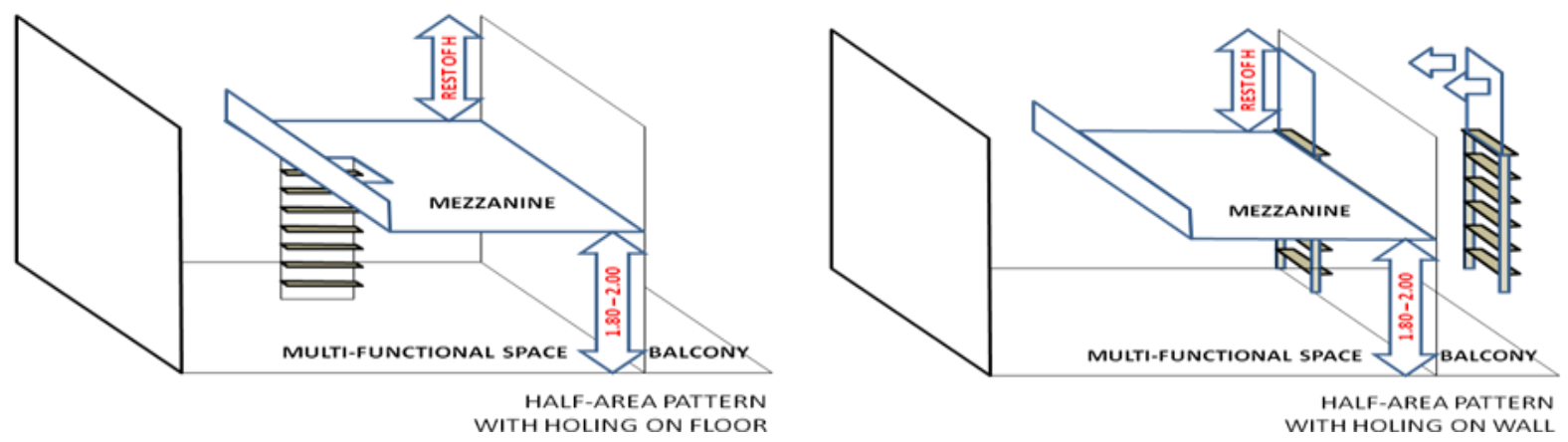

Fig. 3. Patterns of half area mezzanine with holing on floor and wall.

With a mediocre space height, the use of mezzanine space can be specified from any activity that can be done by just sitting and or sleeping. Usage of space so far among others: in addition to being a storing space, this space can also be a rest room and sleeping area. 

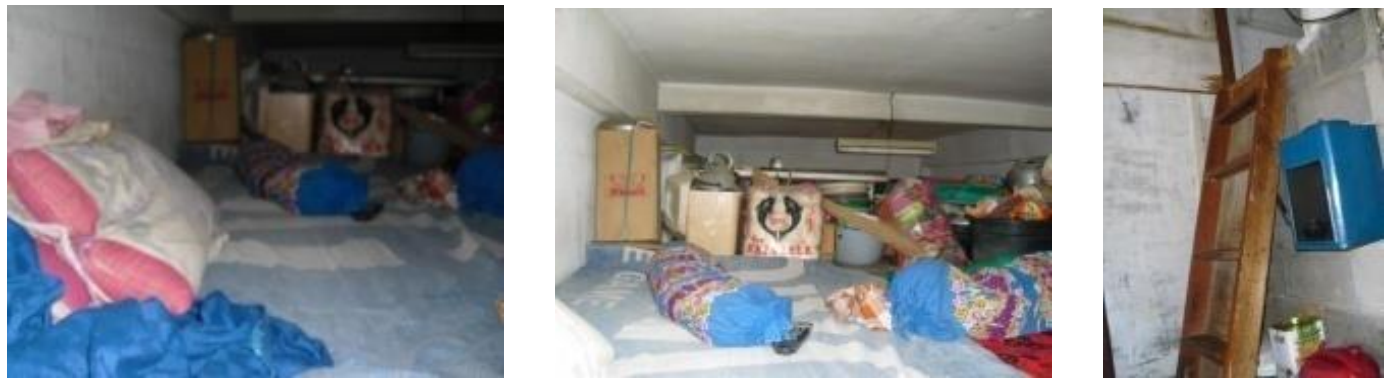

Fig. 4. Illustration of use of half area mezzanine.

\subsection{Patterns of full space area}

Full area mezzanine was mostly applied by residents living in units located at the top floor. Rusunawa occupants who live on the top floor have a distinct advantage because their unit connects directly with the roof space. Occupants who install mezzanine could utilize this space so that the height of the room on the mezzanine can penetrate upwards.
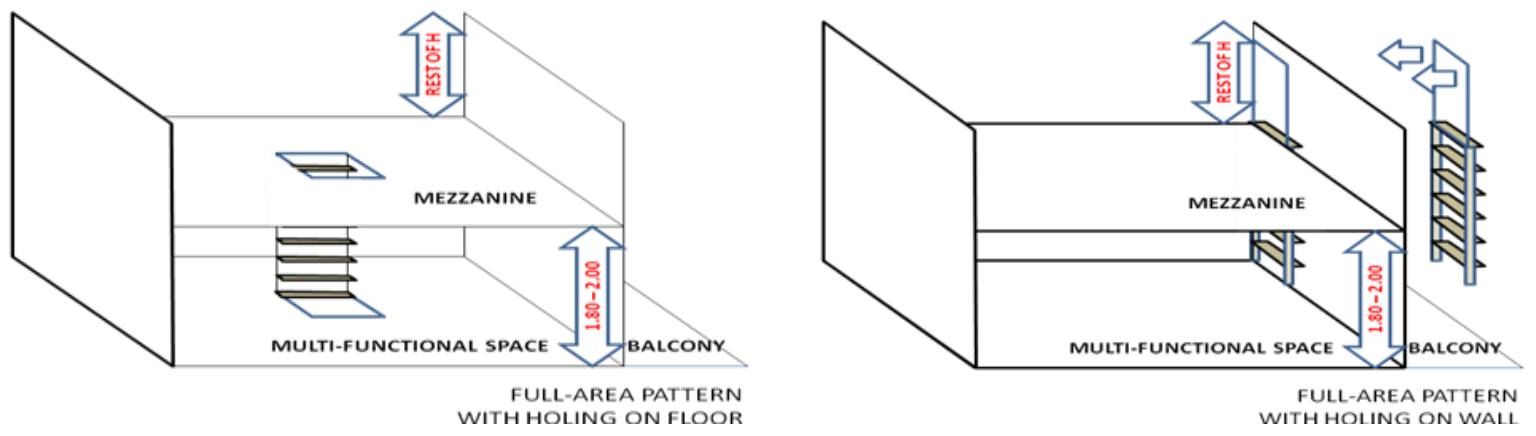

Fig. 5. Patterns of full area mezzanine with holing on floor and wall.

Since the height of the mezzanine space can be determined solely by the occupants, the use of space can also be varied according to the need. The roof space is quite high because this is the roof space of Rusunawa building mass. So the occupant can determine the mezzanine space height more freely as long as they are still below the inside roof line. To be sure this space could be a private living space which is more comfortable. Occupants can use the space for relaxing, playing with children, sleeping, child-caring, studying/working, storing important documents etc.
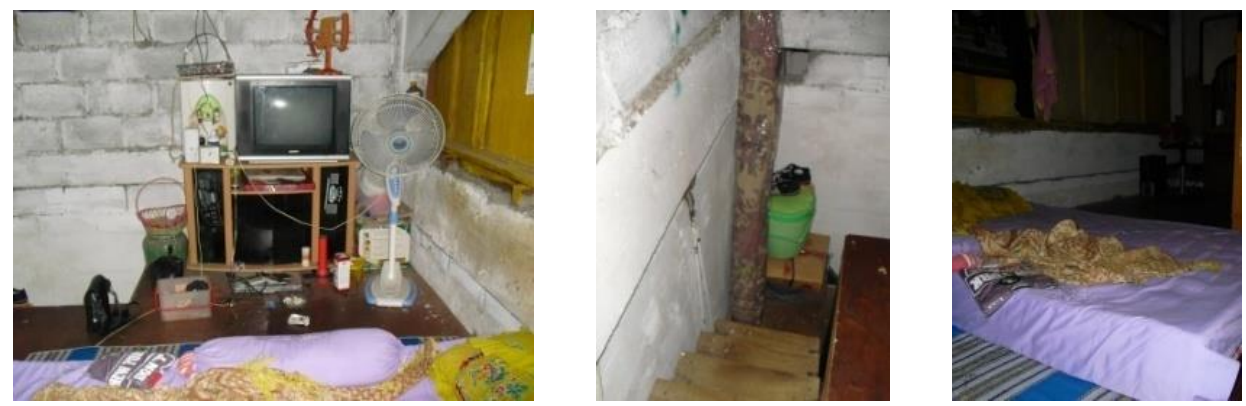

Fig. 6. Illustration of use of full area mezzanine. 


\section{The Adaptability derived from the mezzanine construction}

By installing a mezzanine covering half the area, the area of multi-functional space becomes 1.5 times as much, as residents who installed it would get additional space of half the size of its original space area. This additional space area is very meaningful to the occupants of rusunawa especially those having many household members. Even when the installed mezzanine fills the entire floor of multifunctional space, the occupants will get twice the original floor area.

\section{Conclusion}

The pattern of mezzanine construction that is mostly made by the occupants of Rusunawa in Surabaya is the half the space area. This is logic, as the unit space is too low (less high) for normal mezzanine space in fact they really need the addition space. When the mezzanine space is made full covering the whole area of multi-functional space, the space condition of mezzanine area, either the upper or the bottom space, will be definitely uncomfortable to be lived in due to the low space. Therefore, they insisted to install a mezzanine of half the area, because they really in need the additional space, as the existing space does not allow for the installation of full mezzanine that covers the multi-functional space entirely.

Mezzanine with half the living space is seen to meet their additional spatial needs. Therefore, it can be used as the benchmark in the provision of mezzanine installation options in a modular construction system. If the government intends to provide an opportunity for residents of Rusunawa to do adaptation due to space shortage, it is better if the provision is not only regarding the adequacy of space area and height of the unit, but also including the provision of structural options for the installation of its mezzanine.

By installing a mezzanine or adapting vertically, despite the mezzanine can be installed is only half the size, the mezzanine space created not only can meet the needs of resident's additional space, but this above space could also be a private space which is really needed by a family. The use of mezzanine space is seen dominated by storing. However, inhabitants often utilize it for more private uses, including as a space to sleep and take a rest, besides storing valuable documents.

\section{References}

Bullen, P. A. (2007). Adaptive reuse and sustainability of commercial buildings. Facilities, 25(1/2), 20-31. https://doi.org/10.1108/02632770710716911

Cowee, N. P., \& Schwehr, P. (2012). The typology of adaptability in building construction. Zürich: VDF Hochschulverlag.

Douglas, J. (2006). Building adaptation. London: Butterworth-Heinemann.

Geraedts, R. (2009). Future Value of Buildings. In 3rd CIB international conference on smart and sustainable built environments. Delft.

Kielion, L. J. (2008). Adaptability in Architecture. University of Nebraska-Lincoln.

Lelieveld, C. M. J. L., Voorbij, A. I. M., \& Poelman, W. A. (2007). Adaptable Building Adaptable Architecture. In Proceedings of Building Stock Activation (pp. 245-252). Tokyo.

Moffatt, S., \& Russell, P. (2001). Assessing the Adaptability of Buildings: Retrieved from http://www.eastdunbarton.gov.uk/pdf/APS Corp Assets/APS-CA Assessing the Adaptability of Buildings.pdf

West, B. N., \& Emmitt, S. (2004). Functional design? An analysis of new speculative house plans in the UK. Design Studies, 25(3), 275-299. https://doi.org/10.1016/j.destud.2003.10.002 